\title{
Development of the systematic object event data model for integrated point source pollution management
}

\author{
${ }^{1}{ }^{*}$ W. C. Huang; ${ }^{1}$ S. L. Liaw; ${ }^{2}$ S. Y. Chang; ${ }^{3}$ W. L. Liu; ${ }^{4}$ C. H. Chen \\ ${ }^{1}$ Graduate Institute of Environmental Engineering, National Central University, No.300, Jhongda Rd., Jhongli City, \\ Taoyuan County 320, Taiwan, R. O. C. \\ ${ }^{2}$ Department of Civil and Environmental Engineering, North Carolina A\&T State University, 1601 E. Market Street \\ Greensboro, NC 27411, USA \\ ${ }^{3}$ Department of Civil and Environmental Engineering, Nanya Institute of Technology, No.414, Sec.3, Jhongshan E. \\ Road, Jhongli City, Taoyuan County 320, Taiwan, R. O. C. \\ ${ }^{4}$ Department of Social and Regional Development, National Taipei University of Education, No.134, Sec. 2, Heping \\ E. Road, Da-an District, Taipei City 106, Taiwan, R. O. C.
}

Received 2 February 2010; revised 25 March 2010; accepted 6 May 2010; availaECHonline 1 June 2010

\begin{abstract}
Previous works on database integration focused mainly on the creation of transformation interfaces between incompatible databases built up by different departments of the Taiwan Environmental Protection Administration, ignoring the demands of systematically and flexibly integrated information for advanced pollution control of point sources. To provide a systematic framework for flexible integration of distributed data, this paper presents a general model as the systematic object event data model based on systems thinking, to improve the integration capability of databases. The conceptual database framework for integrated pollution control was proposed as a result of the application of the systematic object event data model. The fundamental part of the systematic object event data model, creation of the object registry database, was put into practice from the year 2008. The object database of pollution source is available to factories in 2009, which helps factories to create and Taiwan environmental protection administration to maintain the consistent object data through the electronic application processes of permits. To construct various event databases that systematically connect to object database would be the following step to more efficiently provide systematic information from systematic data integration.
\end{abstract}

Keyword: Data model; Systematic data integration; Systematic object event approach; Systems thinking

\section{INTRODUCTION}

Controlling point source pollution is the basic strategy for environmental protection access by reducing significant emissions or effluents from industrial plants in respect to air, water, waste and toxic substance. In most of the countries, a factory as a point source are required to apply for installation and operation permits of each pollution aspect according to their activities before constructing the facility and beginning manufacturing process. In Taiwan, factories are additionally required to submit periodical reports of the amount of raw materials, products and pollutants produced while operating with these permits.

Pollution control of point source in Taiwan is governed by the environmental protection

\*Corresponding Author Email: s9326003@cc.ncu.edu.tw Tel.: +886 3422 6541; Fax: +886 34221602 administration (TEPA) and practiced by the environmental protection bureau (EPB) of each city and county government. According to the hierarchical management structure, the data collecting process of point source pollution control in Taiwan can be illustrated as Fig. 1. The data of point source generated from the permit application process and their periodical reports are originally created by factories then arranged by EPB, who is responsible to provide regional point source pollution data to TEPA. The data stream was already simplified by creating and maintaining databases at the TEPA level. However, how to integrated data distributed in more than 22 point source related databases in charge of different departments of TEPA was propose for management of point source (Tzou, 2002). 
The integration of point source pollution data is able to directly improve the efficiency and effectiveness for factories that have more than one pollution discharge activities, which is the situation common to modern industrial plants. Basic and general information of factories are entered once for all corresponding departments instead of several times for each of them. In the same condition, communication between various departments of TEPA and TEPA and each EPB is easier and effective with identical and unified point source data; this is done by saving costs of time and human resources on transformation and correction of inconsistent data. What the most important is, the integration of point source control data is the critical basis for integrates pollution control, which is addressed to deal with cross media pollution through environmental management solution.

The objective to integrate point sources related database was first pointed out in Taiwan in the year 2000 as a part of the national integrated environmental database system (Chen et al., 2010). According to the ten-year action plan, databases of pollution and environmental quality were to be integrated into the system named "the integrated environmental database management system”. In the following four years, the integrated environmental database management system has been maintained by continuously converting data from the original databases (Tzou et al., 2005; Tuzkaya and Gulsun, 2008). However, the result of the project was criticized because of the inefficient integration method, creating various interfaces to periodically convert data into a uniform format from original databases owned by different departments and stored in a new created database. The proposed projects failed due to three reasons. First of all, creation of translation interfaces for increasing databases meant increasing cost and time. Second, the capacity of the database system was limited in its ability to gather all of the data together. The last and the most important point is that the new integrated database system did not easily integrate with other databases.

The continuous collection and analysis of numerous datasets have spatial and temporal differences and interdependencies are required to obtain information necessary for environmental decisions (Pokorny, 2006; Chen et al., 2007; Nouri et al., 2008; Chen, 2009). In the novel environmental informatics field, data integration has been indicated as a collateral issue in model integration and development of information system or application software. Semantically aware approach is recommended to deploy environmental datasets and models (Lee et al., 2007); distributed database are ideal to be operated in compliance with the agent-based approach in environmental information system design (Purvis et al., 2003; Athanasiadis et al., 2009; Huang and Shih, 2009). Regarding the important sights and results from the view of data application, in this study, a more efficient way that constructs data in a semantic logic from the initial step of data lifecycle was developed for systematic data integration with distributed database framework.

The semantic way to integrate data is to follow the logic within the real world since data are symbols, numbers or other presentation of facts. Systems thinking that helps systematically analyze and realize the complex logic within the world of systems, was used

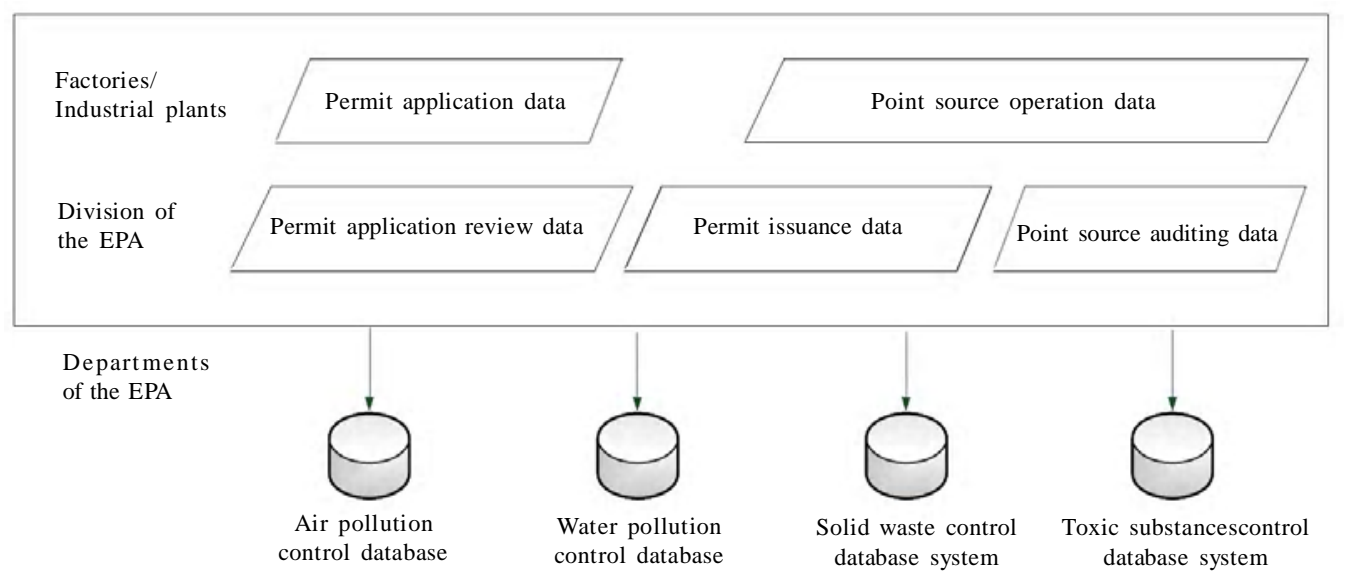

Fig. 1: The data collecting process of point source control of point source pollution control in Taiwan 
to form the methodology. Objects, events and their interrelated relationships that collectively form systems can be regarded as the key elements to interpret and clarify complexity considering both the top-down and bottom-up approaches. Therefore, the systematic object event approach was proposed as the methodology to properly and correctly simplify the reality, which was further applied to identify the description of data.

Based on the above considerations, the integrated database of point source pollution control should be reconsidered and organized from the managerial processes, which are authorized by different departments of TEPA. In this study, the concept of objects, events and their systematic relationships are described and the systematic object event (SOE) data model is proposed in section 2. A more detailed discussion about the managerial tasks for point source pollution control is introduced in section 3. Data requirements and the critical difficulties for data integration are discussed here. Accordingly, the design of an integrated point source pollution control supporting database system is discussed in section 4; it is based on the systematic object event data model. The sequential processes of objectification, eventvisualization and systematical linking of source pollution control related data are also explained in this section. Conclusions were given in the final section. The motivation of this research was first originated in
2004, during the execution of the long-term project (2000-2005) of TEPA. The whole approach was developed, improved and practiced from 2007, which is expected for future application in systematic data integration of environmental data in Taiwan.

\section{MATERIALS AND METHODS}

Exploring a solution to properly allocate source point pollution related data for better data exchange and integration is the fundamental purpose of this study. For that purpose, the primary issue is to create a form that can regulate functions of data sets within databases, which was proposed as a data model, to replace the practicing method, developing various data transformation interfaces. Fig. 2 shows the position of this study, which take data integration into consideration in advance of data storage.

There are various definitions of data model. Pequet (2001) proposed that a data model helps to make the proper representation of reality in the database. In Connolly and Begg (2004), a data model is a methodology for storing, handling and manipulating data, which provides an integrated collection of concepts for describing data, relationships between data, and constraints on data. Brazhnik (2007) claims that data model is used to create specifications for the structured storage of data a database. In this study, data model is defined as the methodology that tells how data abstract and represent reality among

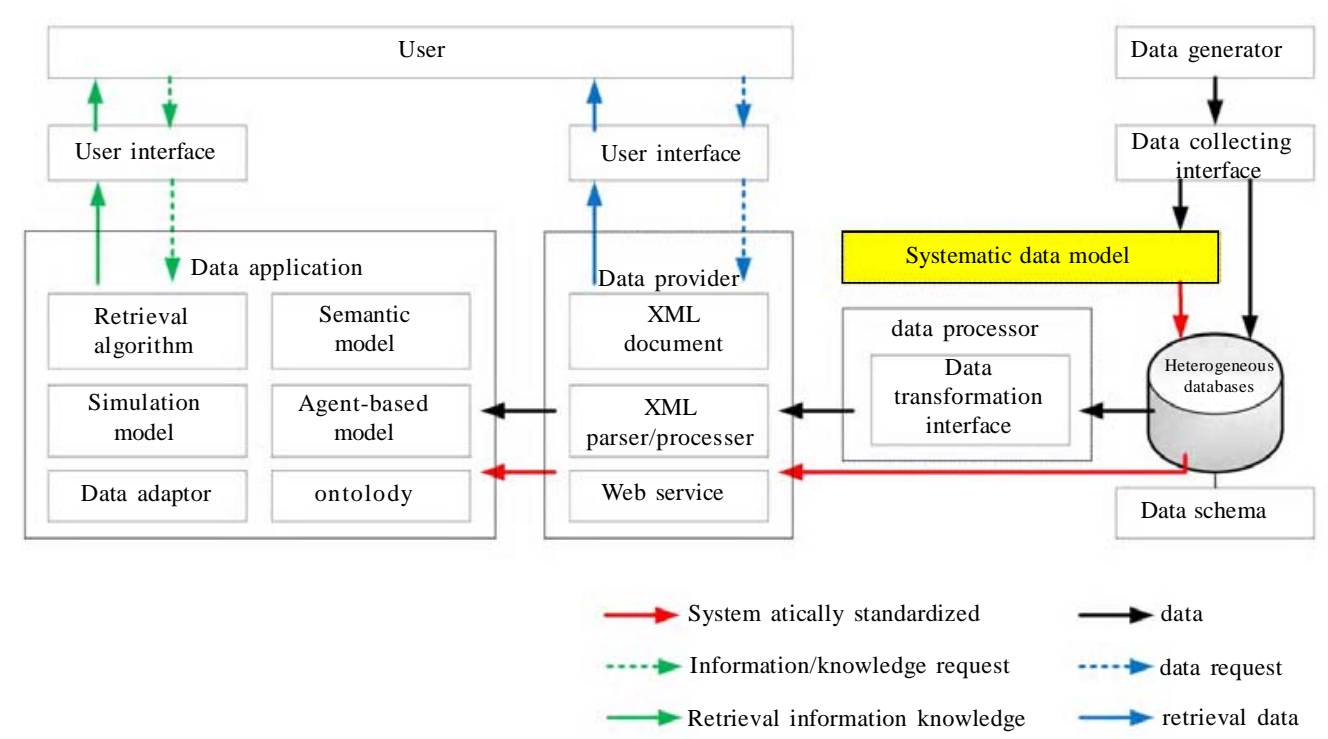

Fig. 2: The position of systematic data model for data integration 
databases in a broader viewpoint, rather than the way that describe the structure of a database. According to Elmasri and Navathe (2007), the systematic data model discussed in this study is a conceptual model, which is the basis in the connection of data management and thus a very important phase in designing a successful database application.

To meet the requirements of advanced environmental management affairs, such as carrying capacity management and control, more natural or human activities should be considered as managing targets to make correct strategies for environment and human health protection. Accordingly, semantics of the humannatural system are critical for creating a data model to process numerous relative data. In order to follow the sense of a human-natural system, systems thinking is applied in this study to systematically identify multifarious properties and hierarchical structures among systems with the top-down viewpoint. On the other hand, data are fragments that should be gathered and constructed to simulate real conditions. This implies that allocation of data has to take the bottomup viewpoint, as in Peckham and Maryanski (1988), to explore a variety of meanings for the semantics by regarding objects as basic elements. For the reason, the systematic approach, based on the holistic view, and the objectified approach, according to the synthetic consideration, are both considered together to propose the systematic object event approach.

\section{The systematic object event approach}

An approach that regards both the top-down and the bottom-up concepts together is necessary to correctly understand complex phenomena in the real world. Based on the consideration, systems thinking is applied as a basis to systematically analyze a problem and objects and events thinking is used to define basic elements of a problem. The systematic object event approach was developed accordingly to reconstruct different structures of systems or represent the course of the problem.

Systems thinking emphasized on applying the characteristics of systems to understand and analyze a problem as parts of an overall system (Andrew and Richardson, 2008; Hsu and Hu, 2008; Petkov et al., 2008). Two basic principles of systems thinking, entirety and completeness, are drawn from the literature in order to think of system structures from both the holistic and reductive view-points (Rubenstein-Montano et al.,
2001; Moore and Ausley, 2004; Skyttner, 2006; McLaughlin, 2009). The conceptual framework provided by systems thinking has been particularly useful in the understanding and modeling of dynamic processes (Ozel and Kohler, 2004). The critical viewpoint of systems thinking is the entirety and completeness of a dynamic system, which should be referred to in developing the approach for object recognition and recording.

The concept of objects is used in the computer science field as the name of object oriented programming, object oriented analysis, and object oriented databases. It emphasizes thinking of objects as complete functional identities, neglecting their inner functional parts and utilizing them repeatedly. Objects thinking is an instinctual way if thinking of human when encountering something the unknown. A physical object can typically be visualized or utilized as an opaque black box, where of all the internal processes are hidden. People learn to use the holistic object first; for example, most will be able to drive an automobile without understanding every component of it. However, identifying objects that comprise the real world is not as simple as to do so in the virtual environment. A virtual object is designed and created for specific purpose, which has clearly defined properties and fixed interactions. Objects in the real world on the contrary are gradually defined with improving technology and knowledge because of uncertainties within the natural environment (Tehrani et al., 2009).

The concept of objects, in this study, is from physical objects in the environment; their properties and operative activities are based on the awareness that data are abstract descriptions of real objects. By understanding that an object is a unique entity which has specific properties, and that a system is a functional entity composed of smaller parts, an object can be distinguished in order to divide and define a system from its environment (Huang and Liaw, 2004). Accordingly, an object can be converted into a system that consists of smaller objects while preserving the system's structure in its entirety as illustrated in Fig. 3. The life supporting environment is a four dimensional spatial-temporal system that contains countless objects and interacting processes, in which phenomena should be abstracted in a dynamic and synergistic manner. For this reason, systems thinking also take dynamic changes into consideration besides the thinking of objects. In order to properly express the dynamic processes caused 


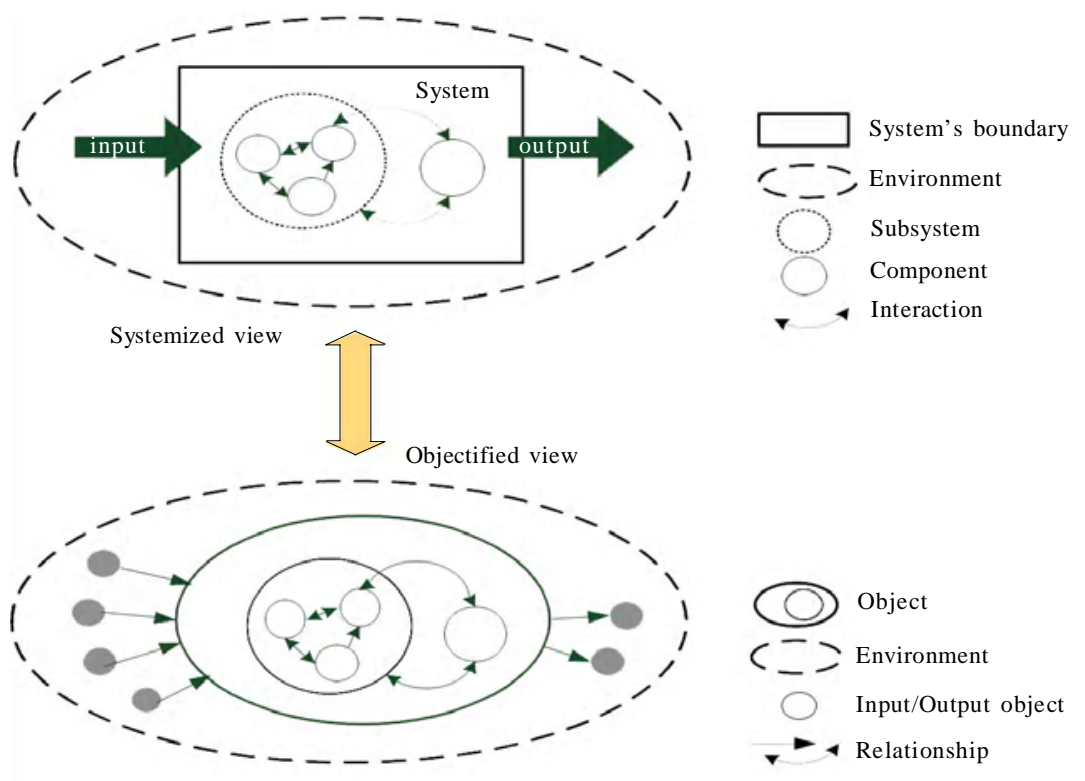

Fig. 3: The concept of systemized and objectified viewpoints

by the interactions of objects, the sequence of actions or reactions of a specific object are defined as events.

An event is the entity identified along the time line, which is used to indicate the changes of an object. The causes, reacting process, and effects of objects over a period of time can be next identified on the basis of the definition of an event. With the definitions of an object and event, the systematic object event approach is presented here based on systems thinking to systematically explain the reality by recognized objects and events. In the systematic object event approach, any object is a unique whole with a set of specific attributes, behaviors and relations and also a functional system that makes reaction to external inputs and produce outputs. The process of an object reacting with its inputs, changing its own condition, and producing outputs during a period of time is an event for a certain object. Internal components of an object may interact together to generate a set of output results during an event, while the overall property of the object dynamically changes with time. Complex systemic problems are able to be systematically identified by defining objects and their events, as an animation can be well presented by properly organized consecutive frames.

The description of objects, events and systematic relationships

With the logic of the systematic object event approach, data generated to describe a part of reality can also be arranged, classified, defined and organized reasonably as descriptions of objects and events of a systematical structure. According to the definition of object, the uniqueness of an object can be defined by its special property, which is more specifically sorted into three groups: attribute, behavior and relationship. "Attribute" is the category that refers to the measurements of an object; for example, a factory has attributes such as location, capital, size, area and so on. Data included in the type of the attribute offer a thorough understanding of an object, which helps to differentiate the object from others within the same or similar environment. The category "behavior" is grouped by functions or abilities of an object; for instance, production and wastewater discharge are behaviors of a factory since it has the function to produce products and generate wastewater. Reactions of an object that are caused from particular inputs are known as well as the behaviors of an object. Behaviors of an object may be triggered by stimulants that produce specific reactions and changes in the object, such as raw materials or new orders of a factory. Unlike attributes and behaviors that indicate the features of an object itself, relationships reveal the connections with other objects. The systemic framework and structure of an object are identified in the category "relationship" to systematically link relative objects together. According to the definition that an event is an identified changing process of an object 
along an irreversible timeline, each event is unique from its characteristics. Input and output are two critical data types to an event that indicate the causes and results of the reaction. The properties of the object changed during the event are also necessary statements of proper description of an event. Besides, temporal attributes of an event emphasize times, such as the beginning or ending time or duration of an event. Relationships of events are used to describe other objects or events related to this event, for example, a sponsor to an annual conference as an event. In accordance with the discussion above, descriptions of objects and events can be further sorted and defined as shown in Fig. 4. An object essentially needs its identification, attributes, behaviors and relationships to be defined. And an event requires the records of its identification, attributes and relationships, and inputs and outputs to be fully presented.

\section{The systematic object event data model}

The SOE data model, based on the systematic object event approach, is proposed in order to provide a basic standard to identify raw data by their semantic meanings. According to the sorts of descriptions that are used to give correct impression of objects and events, the SOE data model was designed with two sub-modules, the object registry (OR) module and the object event (OE) module. The data types that are concerned in the two modules are illustrated in Fig. 5.

The OR module contains three data types to well organize the basic and static characteristics of an object, and the OE module includes the data types to properly allocate historical records of an event. The type of "input data" is designed to impress the causes an event, which may present by either the substances or circumstances that initiated specific functions of an object. Thus, input data can be recorded by indicating either objects or events depending on whether or not the input events of the input objects are identified, and so can the output data.

Different to the existing data models such as the relational, object oriented and object relational data models, the SOE data model is more capable to

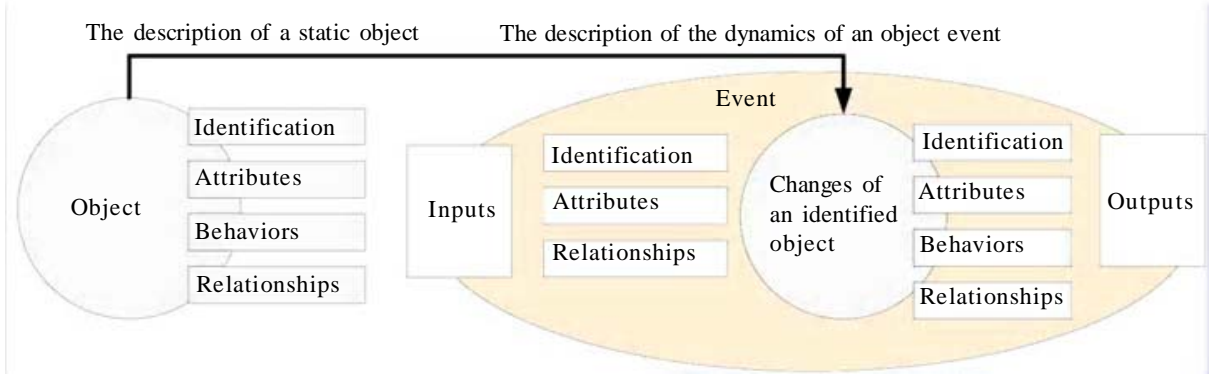

Fig. 4: The sorts of descriptions of objects and events

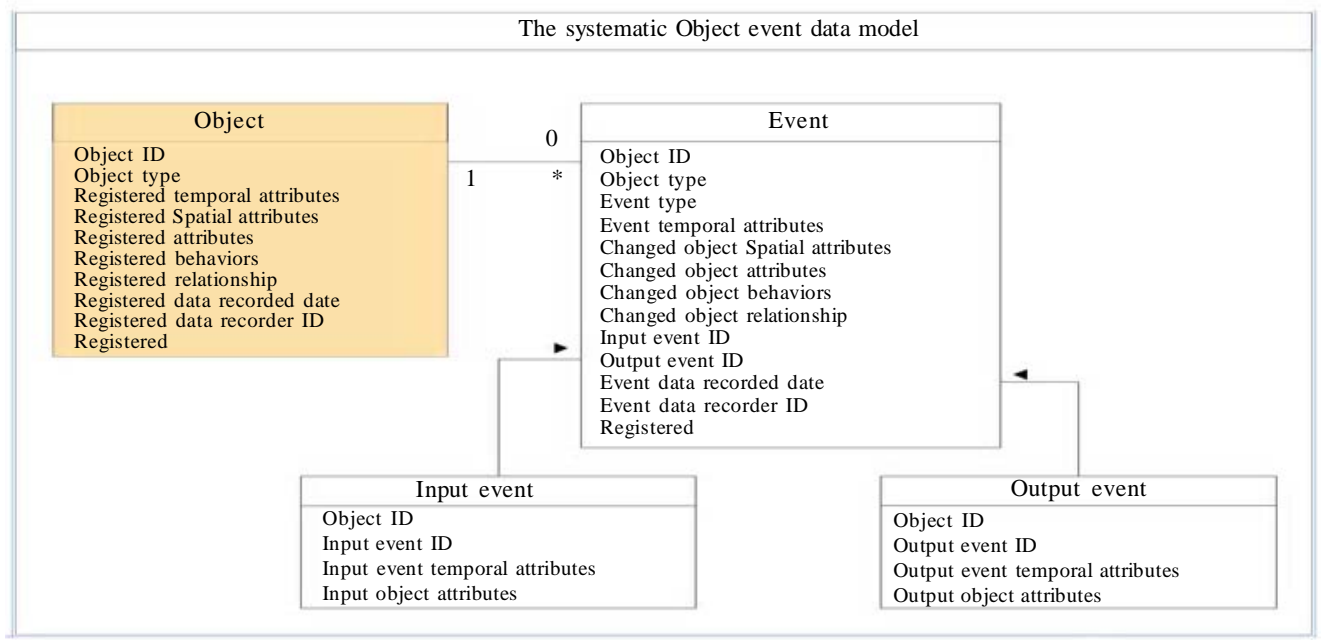

Fig. 5: The conceptual structure of the SOE data model 
effectively model and describe the structures and interactions among objects or inside systems. The fundamental assumption of the relational model is that all data are represented as mathematical relations (Maurer et al., 2001). Since relations between attribute should be known and defined, relational data models are poor choices for data transparency and portability. For the reason, the relational data model is not a kind of spatiotemporal data model, so the ability of interpreting internal structure, temporal changes and the application flexibility and practicability are relatively less than the object oriented and SOE data model. As for the object-oriented and object relational data model (Huang, 2003; Shi et al., 2003), they are able to present static systematic structure through the concept of objects and relationships. However, dynamic processes that happened to objects cannot be well linked and presented in these data models.

On the basis of systems thinking, the SOE module combines the practical concept of objects and events and improves their ability to interpret real-world phenomena by identifying systematic relationships. Therefore, the data model is capable to better record facts with not only the states of changes of an object itself, but also the states of input and output events which are the causes and effects of an object event. The input and output data of events are designed to record the known reactions between objects and can be continuously modified when new facts are discovered. Uncertain or unknown parts of the world can be gradually recognized, discovered and speculated upon by recording what is known. Complex systems can even be reconstructed based on the SOR and SOE records as a sequence for a specific space and time, as a four-dimension simulation and be represented with the same logic.

\section{Tasks of point source management in Taiwan}

Control of point source pollution is the basic mission for the protection of human health and the environment, which TEPA is in charge of. Point source discharges are typically controlled by issuing a discharge permit that is subject to various environmental protection conditions and laws designed to ensure that no irreversible damage occurs as a consequence. According to the latest point source related laws and regulations in Taiwan, such as air pollution control act, water pollution control act, waste disposal act and toxic chemical substances control act, managerial tasks divided into different pollution aspects can be organized similarly to Table 1 . It is shown that an industrial plant has the same target for point source management in four main aspects of environmental control which include air, water, waste and toxic substances. Moreover, facilities and pollution treatment processes in a factory are concerned with air pollution control, as well as wastewater control. The two categories of control measures that apply to a factory regarding inspections are permit assurances and supervision of periodical report of emissions.

Data related to point source control cones mostly from the measures required by industrial plant registration, permit application and annual reports. For that reason, analysis of objects and events for data arrangement should use these measures as the basis for consideration of data integration of point source management. Data redundancy, caused from independent control measures of each department without consideration of integration, is a cause of concern to both TEPA and factories. The SOE data model with the systematic object event approach is useful to rearrange point source pollution related data in a systematic view, concerning the consistency, accuracy and completeness of identification of managerial targets and the analysis of dynamic conditions in a systematic view.

Objectifying control measures to unify the managerial targets is the first step that is needed to solve problems from data redundancies among the databases which belong to TEPA's different departments. Once the managerial targets are systematically unified, industries do not have to register the data which is similar to that of TEPA's different departments. Unified registration data provides sound basis to orderly record periodical data from a specific industrial plant by the same referring path, which is the critical point to accomplish further integration. With the consistent reference, TEPA can more easily find faults within the reports submitted from factories by verifying and comparing data from industries in the same type. Also, advanced information for integrated environmental management, such as pollution intensity in a certain area and time period, can be systematically gathered and presented for better understanding based on unifying managerial targets in a systematical way including the concerns of spatial and temporal attributes. 
The SOE data model for Taiwan's point source pollution management

Table 1: Targets and contents of tasks of point source control in Taiwan

\begin{tabular}{|c|c|c|}
\hline Aspect & Control targets & Control measures \\
\hline $\begin{array}{l}\text { Air pollution } \\
\text { ( Air Pollution } \\
\text { Control Act, 2006) }\end{array}$ & Operation units that emit air pollutants & $\begin{array}{l}\text { issuing installation permit } \\
\text { issuing operating permit } \\
\text { supervising annual emissions reporting programs } \\
\text { supervising monitoring or analysis reports }\end{array}$ \\
\hline $\begin{array}{l}\text { Wastewater (Water } \\
\text { Pollution Control Act, } \\
\text { 2007) }\end{array}$ & $\begin{array}{l}\text { Factories or sewage systems that } \\
\text { discharge wastewater into ground } \\
\text { water bodies }\end{array}$ & $\begin{array}{l}\text { wastewater treatment plans } \\
\text { issuing permission } \\
\text { supervising operations } \\
\text { supervising inspections of emissions and documenting } \\
\text { records } \\
\text { supervising automatic monitoring reports }\end{array}$ \\
\hline $\begin{array}{l}\text { Industrial solid waste } \\
\text { (Waste Disposal Act, } \\
\text { 2006) }\end{array}$ & $\begin{array}{l}\text { Industries such as mining field, } \\
\text { hospital, waste treatment organization, } \\
\text { laboratory and others identified by } \\
\text { TEPA }\end{array}$ & $\begin{array}{l}\text { industrial waste clearance registration and inspections } \\
\text { issuing permission of import, export, transit and } \\
\text { transshipment of waste } \\
\text { issuing permission of public or private waste disposal } \\
\text { organizations } \\
\text { supervising solid waste export report system }\end{array}$ \\
\hline
\end{tabular}

Environmental management tasks are comparatively complex and variable, which means that normal method of data modeling will be able to arrange the decision supporting data. Normal methods failed to integrate environmental data because they construct a new database system by gathering data from independent databases through various interpreting interfaces without thoroughly and systematically analyzing the meanings of data (Liaw et al., 2005). Accordingly, the SOE data model with the concept of systematic objects and events was proposed and applied to the design of an integration structure of distributed database systems by integrating point source related data at first. Extensibility and flexibility of a database are now the essential requirements to contribute to usability of data and data integration (Seltzer, 2005; Liaw et al., 2006). In the SOE data model, data consistency is considered by identifying unique object identification among distributed databases through the objectifying process. Dynamics of objects can be flexibly created to the virtual integrated system through the format of object events, which confirms the ability of the data describing them to be integrated. The details about using the SOE data model for point source pollution management are introduced in the next section as the first stage to construct an integrated database system for national environmental management.

\section{RESULTS AND DISCUSSION}

In this section, a flexible structure for systematic integration of data in distributed databases for integrated pollution control of point sources has been designed. Dynamic changes within a specific system boundary are regarded as the synthetic result of constituent objects, events and their interrelated relationships. The divisions of managerial tasks of point source pollution control for the common purpose of realizing and controlling pollution effectively was systematically clarified. Control of wastewater discharge was chosen among the four control aspects as a demonstration to show the event-recognizing process in detail. Following this, the overall result of identifying all objects and events related to integrated point source control was presented as the foundation of the database system structure. The blueprint of the integrated point source pollution control supporting database system for TEPA is based on the systematic object event data model was proposed and discussed as the last part of this section.

\section{Object analysis of point source management}

First of all, the various registration forms that are required during the permit application process for different pollution control aspects were gathered as the basis of object identification. Attributes of the physical objects that are targets of pollution control can be differentiated and identified. The systematic structure of relative objects can be illustrated according to the result of the object's identification as shown in Fig. 6. 
Two viewpoints, objectification and systemization, were implied in Fig. 3 to recognize and identify the main target of point source pollution control of an industrial plant or a factory. A factory is a unique object with particular attributes, behaviors, and relationships. Some details of attributes, behaviors and relationships were addressed as examples in Fig. 6. Operational processes that present certain functional abilities of an industrial plant are categorized as behaviors of an object. The manufacturing process is the behavior initiated after resources had been imported, products exported, and waste disposed of. The subsidiary relationship belongs to the category "relationship" in Fig. 6 was used here to describe the systematic linkage of an industrial plant to its parent company.

From another viewpoint, an industrial plant, which is a practical system, can be systematically deconstructed to form some functional groups as its components. Categories which are suitable for managerial requirements can be identified within each type based on the specialty of the hierarchical structure of a system. From the logical layer to the physical payer, an industrial plant can be systematically broken down into certain functional groups with classes of physical objects as shown in Fig.7. Categories for classification of objects are in white and groups of physical objects are in grey. With the general concept to construct a system with structured objects, categories or groups of objects can be easily and flexibly changed by replacing relationships of events without breaking down the complete structure of a system. The identification of object classes here is the basis of design of the object data table. On the basis of recognition of objects, the event analysis of the identified object groups was progressed following the dynamics of an industrial plant.

\section{Event analysis of point source management}

To identify point source pollution control related events of an industrial plant, the components that produce and control pollution behaviors should be recognized as the first step. For example, the manufacturing activity consists of the interactions of raw material, water, power, fuel and so on. One or more events can be used to illustrate the dynamics of each behavior according to how explicit the details are

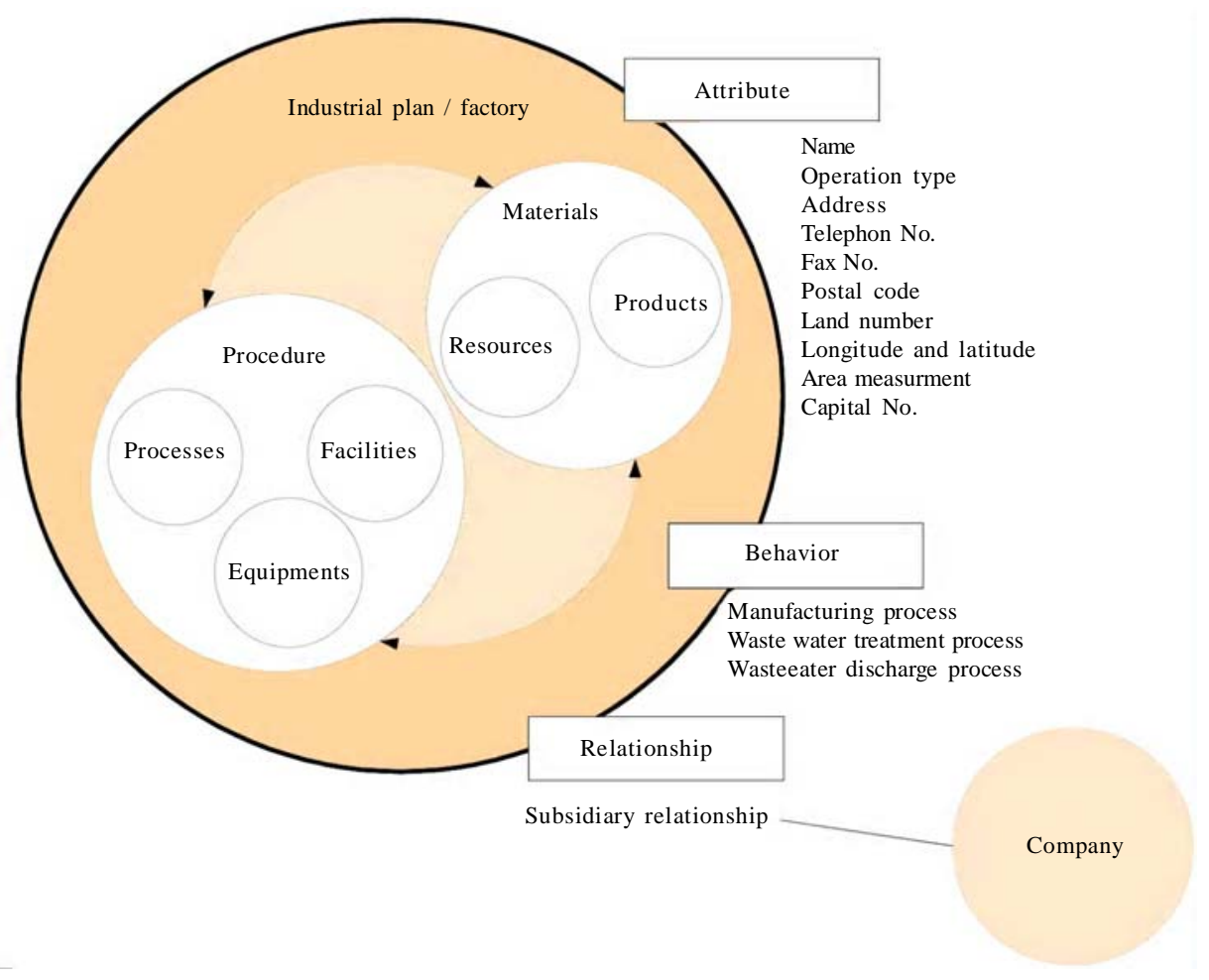

Fig. 6: The concept diagram of an objectified point source 
required to be for managerial purposes. For the purpose of point source pollution control, events of manufacturing and pollution control activities in four aspects, air, water, solid waste and toxic substances, are concerned in this study. Sequential events included in the manufacturing and water pollution control activities are chosen as a sample to introduce the process of event analysis in detail following the results of the pollution control requirements, object identification and linkages of component parts and the system's behavior.

\section{Events within manufacturing process}

Based on the data in a periodical pollution report, the manufacturing process may be regarded as a systematic event that consists of partial events of raw materials, power, fuel, and water usage, and events of producing products, waste gas, wastewater and solid waste. These partial events correspond with a specific type of constituent object of an industrial plant, as shown in the upper part of Fig. 8. Based on this logic, each event can be easily extended or modified if necessary without altering others, and a synthetic event can be flexibly integrated by defining a specific system boundary.

\section{Events within water pollution control}

Regarding the regulations for industrial wastewater, water pollution control related activities can be divided into wastewater treatment and wastewater discharge, by the physical boundary of an industrial plant.
Wastewater storage and treatment are the two processes restrained inside an industrial plant which are included in the wastewater treatment processes which have to be reported periodically. Activities of wastewater outside of an industrial plant include wastewater discharge to surface water bodies, groundwater or marine, outsourcing treatment or soil treatment of wastewater and reuse; these are necessary information requirements for water pollution control. Therefore, events within water pollution control can be identified by components based on the latest managerial requirements.

The result of procedures and events concerned in treatment of industrial wastewater is shown in the middle part of Fig.8. The treatment flow starts from "wastewater" in the dotted red box because it was previously identified in the end of manufacturing process. In reality, wastewater may be transported to a treatment facility, storage facility, or directly discharged. The wastewater flow identified here satisfies the basic requirements of the latest point source control in a water pollution prevention aspect, which is not explicitly a real world workflow in an industrial plant. However, more details can be easily added to this resulting analysis with the systematic object event approach since the structure and flow both originated from systematic conditions of the real world.

Wastewater discharge is the other part that is restrained by the water pollution aspect of point source control. In the same way, the process of wastewater

\begin{tabular}{|c|c|c|c|c|}
\hline \multicolumn{5}{|c|}{ Industry / Factory } \\
\hline \multicolumn{2}{|c|}{ Materials } & \multicolumn{3}{|c|}{ Procedurs } \\
\hline Resources & Products & Processes & Equipments & Facilities \\
\hline Raw material & Product & $\begin{array}{l}\text { Manufacturing } \\
\text { Process }\end{array}$ & Air pollution control & Operation field \\
\hline Water & Toxic substance & & Monitoring device & Chimney (flue) \\
\hline Fuel & $\begin{array}{l}\text { Exhaust } \\
\text { (Air pollutant) }\end{array}$ & & Measurment device & $\begin{array}{l}\text { wastewater } \\
\text { treatment facility }\end{array}$ \\
\hline Power & Industry & & & $\begin{array}{l}\text { wastewater } \\
\text { discharge outlet }\end{array}$ \\
\hline $\begin{array}{l}\text { Additive } \\
\text { chemical }\end{array}$ & Solid waste & & & $\begin{array}{l}\text { wastewater } \\
\text { storage/reuse facility }\end{array}$ \\
\hline
\end{tabular}

Fig. 7: The systematical analysis result of an industrial plant 

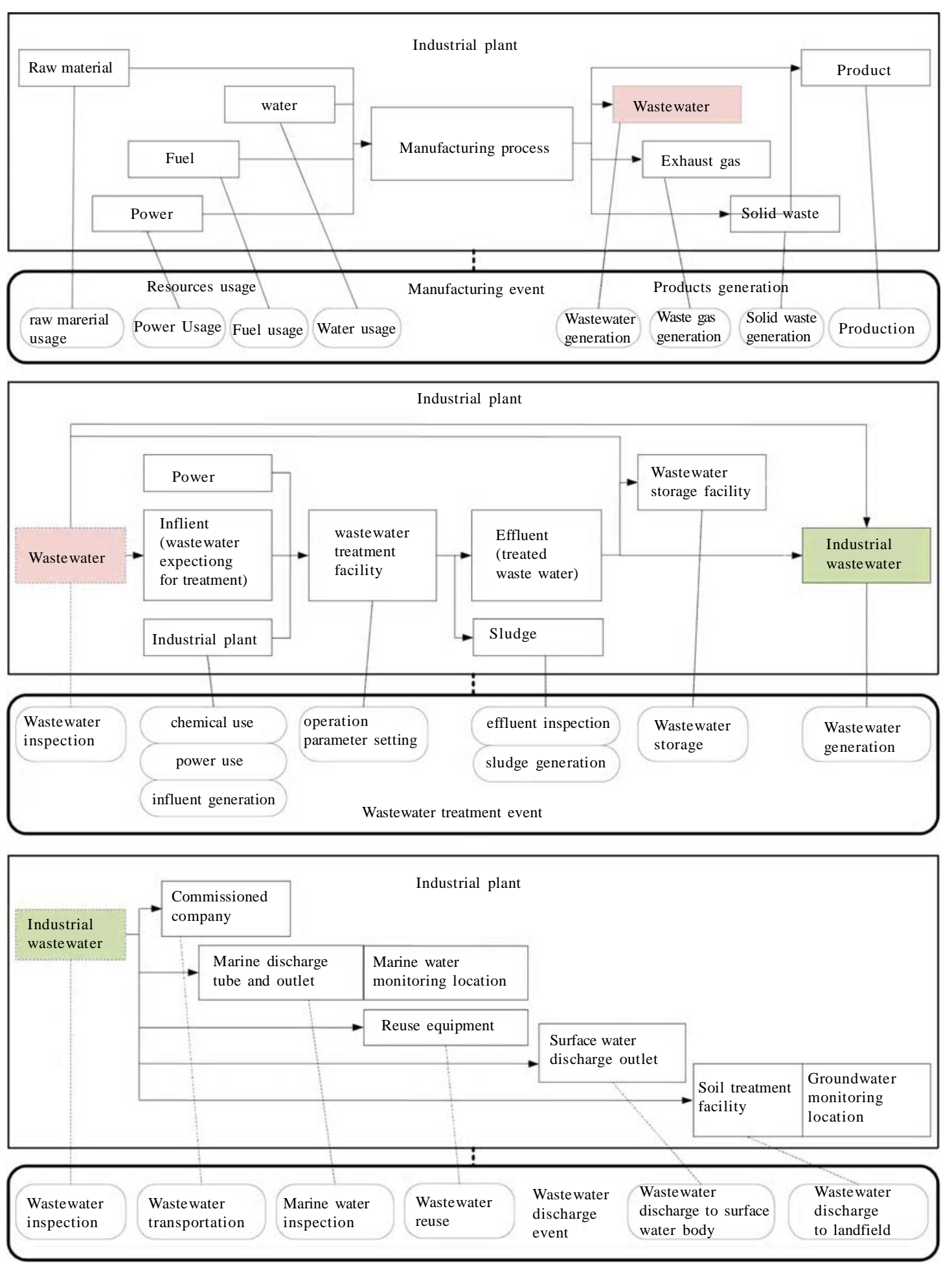

Fig. 8: Objects and events within manufacturing, wastewater treatment wastewater discharge processes 
discharge that consists of certain objects was defined according to relative regulations in the bottom part of Fig. 8. The wastewater discharge flow started from the dotted green box labeled "industrial water" that was already defined as the wastewater which was prepared for release from an industrial plant. Concerning the regulated manners of industrial wastewater discharge, the procedures of outflow include outsourcing treatment, reuse, or discharge into marine, surface water body, or land. Each manner can be seen a type of event because of its special features.

Accordingly, all of the processes and events can be gathered and merged into an overall process for the concerns of point source pollution control with originated systems thinking. Similarly, the processes and events were analyzed and all the results can be finally completed as an integral. Within the scope of an industrial plant, the structure and mechanisms constructed by objects and their interactions can be clearly identified. Events describing segments of dynamics are correspondingly defined with systematic relationships. Out of all of the constraints of point source pollution, the manufacturing process was newly identified and has become a unique event that can offer enough information for different pollution controls. Other identified events are sequentially related and able to be additively recorded. The result of systematic object event analysis of an industrial plant in this section would apply point source pollution control to a systematic structure for database design.

Design of the integrated point source pollution control supporting database system

Based on the results of the systematic object event analysis of an industrial plant, data elements required in relative application and report documents of point source pollution control were rearranged similarly. All the original data items were retained for satisfying original managerial requirements but additionally categorized and allocated into object and event data tables with the concept of object event descriptions. Some new data elements, for example, those for indicating the input and output objects or events, were added for further systematical integration. Following the object event analysis procedures, 20 object data tables with necessary data elements were first created. Not all the objects discussed in the previous section was included here to make a corresponding object data table because some of them are not the subjective object of the events required for pollution control, such as raw materials or products are input objects of a manufacturing process during the manufacturing event. Based on the relative regulations of point source pollution control, object tables were created for the managerial targets, such as manufacturing process, treatment devices or facilities and discharge outlets, to be the unified references of various object events.

It is shown that factory and processing process are the common objects for four pollution control aspects and other objects are special for each pollution control. For the reason, data elements that are required to address the basic information of an industrial plant and its manufacturing processes in the application forms of installation and operation permits in different aspects. The identification of the same industrial plant is unified here to represent the four different kinds of control codes. With consistent object identification, activities that are concerned in point source pollution control tasks were systematically organized by 49 event data tables with the necessary data elements. Each event data table is designed to record a specific activity that happened to a specific object relates to pollution generation, treatment or discharge.

The architecture of the object event database system should be accomplished by a distributed databases framework for various authorized departments to maintain cooperatively and communicate conveniently. For the reason, the point source pollution control supporting databases system was constructed by two parts, object databases and event databases, as illustrated in Fig. 9. Concerning the organizational structure and the corresponding managerial affairs, the object database should be handled by the central information office, as the department of monitoring and information management of TEPA. The event databases, on the contrary, are respectively maintained by different pollution activities monitoring and controlling departments to help their individual managerial procedures.

The object event database system can satisfy various data requests from advanced application system to provide systematic environmental information, as the procedure shown in Fig. 2, through integration of object event data in different ways. Once the application system accepted a query string from user, a 4-step procedure search and reply action, which is addressed in the bottom of Fig. 9, would be activated for provision of required data. The four steps include: 
Step 1: Search object registration database for fitted objects by object ID and structural attributes according the parsed result of data query string;

Step 2: Send back the object registration data with systematic relationships;

Step 3: Search event databases for fitted events by object ID, event ID, and temporal attributes of events; Step 4: Sent back the suitable event records with causal relationships in a temporal sequence.

Based on the four steps, an object event database system is efficacious to provide fitted and richer data for diverse data requests, especially for the requirements of systematic information. For example, for EPB to make an environmental assessment of a regional development plan, it is necessary to know the existed point sources and their activities in a specific area, so that the query string of data would be parsed as constraints of location in a specific period. The spatial constraints would be first sent to the object registration database to select qualified objects from their spatial attributes. The selected object IDs would become the arguments combined with the temporal constraints for searching the fitted event data among distributed event databases. After collecting all the relative datasets, the object data can be first mapping with geographical information system to reveal the spatial correlations within the point sources in the certain area. Besides the static expression of the specific area, event data that describe the dynamic changes of identified point sources can represent the past activities within a certain period by screening the temporal attributes. Designed especially for system dynamics modeling, STELLA can also be used as a convenient differential equation solver or non- system-dynamicsoriented modeling practices (Costanza, 1987). Data that recorded as the SOE data model can be easily and efficiently integrated into a systematic structure to represent the real world phenomena, which helps in the advanced analysis or understanding of current results or consequences.

Regarding the point source pollution control processes of TEPA, each industrial plant should be required to submit its registration data when applying for installation permit before establishment. Completeness and accuracy of data were considerations for the issuance of a permit. Once an industrial plant got its installation permit and completed construction, they would need to apply for an operation

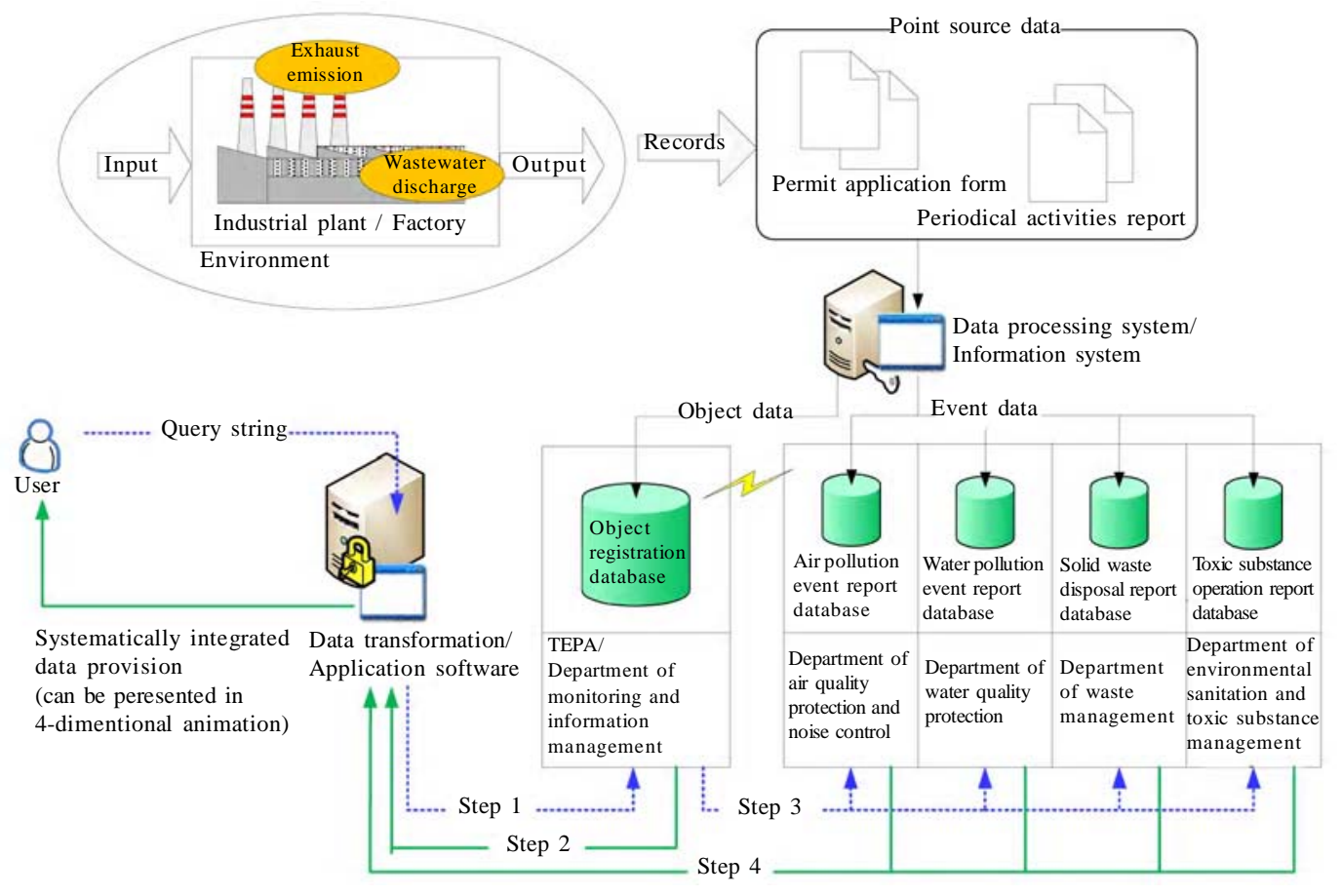

Fig. 9: The systematic object-event database framework for integrated pollution control of point sources 
permit before legally beginning production. When applying for an operation permit, the administrative organization should check the accuracy of object registration data and behavior managerial organizations should check corresponding events that need to be controlled during the operation of an industrial plant. With the regulation of periodical point source report, events data can be maintained and accumulated independently by their responsible departments. However, identical identification of an object and event and categories of data elements are a firm basis for making systematic integration of data for representing the process within a given space or period.

Following the SOE data model for systematical integration of data, TEPA has already accomplished the first step in creating a general referenced databases system for object registration using the permit application procedure (Chu, 2008). Now industrial plants are able to apply for installation and operation permits through the internet which constructs an object registration database simultaneously through the environmental management system (EMS) website found at http://ems.epa.gov.tw/.

This information system provides the one-stop service for point sources to register their basic static information, which is called "baseline data" in this system, as to register the object data through the object registration system. Industrial plants do not need to inform different departments of TEPA individually if some static properties change. With the consistent object database, event databases can gradually be built up from both transformation of existing databases and newly designed database for new managerial requirements without any confliction. However, the EMS now takes the way that linking to previous independent application systems (the exhausted gas treatment and emission report system, the wastewater treatment and discharge activities report system, the waste discharge and transportation activities report system and the toxic substances operation report system) to store and operate data without consistent structure. To rearrange the existed datasets within inconsistent databases into event databases for storage of periodical report data in diverse pollution aspects such temporal and systematical data in a systematic way is exactly the following task on the basis of the object registration system.

The systematic object event database framework is not limited as a structure for integration of pollution control data based on environmental concerns. Economical or social data relating to an industrial plant that are in charge of other managerial organizations can also utilize this model to further understand an industrial plant if data are altered to fit the systematic object event concept. More details can be revealed from the distributed database systems without ineffective and repeated system transformation due to new databases creation. For advanced environmental management, sustainable environmental management, more supportive information are capable to be generated by integrating both pollution activities and environmental quality data with the systematic object event database architecture.

\section{CONCLUSION}

Compared to uncontrollable natural activities, point sources are solid targets which can be more clearly identified for environmental management. Data from point sources have been accumulated since they were required in the application process of permits and periodical reports in relative regulations. However, it was found that these generated data were not capable to integrate effectively because of their inconsistency which was caused by different managerial procedures and corresponding databases built for different environmental concerns. The independent databases can support managerial tasks in a specific pollution control field, but not integrate efficiently; this doesn't feed the new need of advanced environmental management for sustainable development.

In this study, systems thinking and the concept of differentiating objects and events were app lied to give reasonable and systematic explanation of real world dynamics. With the function of properly describing physical phenomena, the systematic object event approach was proposed to define a new data model for systematic arrangement of interrelated data among databases. The SOE database structure that systematically allocates data with the sense of objects and events can be more efficiently assembled to represent a desired past constrained in a given specific spatial and temporal scope.

Procedures and types of data elements that are concerned and collected for point source pollution control were defined by the SOE data model as the demonstration of its application. An industrial plant and its restricted components were clearly identified as objects and the data required for application of 
permits were put into categories of identification, attribute, behavior, and relationship. According to the results of object analysis, constrained processes gave corresponding operation records were then summarized into various events. The items required in the periodical report were also grouped into the categories of event description.

Data describing different segments of real world dynamics should be assembled and arranged in a systematic structure for a more correct simulation of the real world. Therefore, point source pollution management affairs of TEPA were chosen as to demonstrate the application of the result of the SOE data model. Object registry and object event schema were proposed as two parts of the SOE data model to Figure out the problem of systematical integration of data for point source pollution control.

In this paper, the point source pollution control was presented as the case study because that TEPA focuses on this part to establish information management system in recent years. As the reviewer's opinion, mobile sources are important for pollution control, especially on the consideration of air pollution in urban area. The data of mobile source pollution are able to be processed and integrated if they were generated or arranged with the SOE data model. Take advantages of the novel techniques, such as the global positioning system (GPS), a mobile source can be correctly tracked as an event data of it and recorded the specific status with temporal and spatial data. In this way, the pollution of a target area, including line source, can be calculated and assessed by integrating data within a specific geographical scale and time frame. Environmental monitoring works in Taiwan does not go that fast to establish detail data of mobile sources yet, but this work will definitely be done in the near future. With this vision, the SOE data model is strongly recommended to be extensively applied in environmental databases for better decision making of pollution control.

Based on the results of this study, the application scale of the SOE data model can be further extended: creating event databases in also economic and social aspects for the total management of industrial plants; adding object databases of natural objects and databases of natural activities monitoring event for integrated environmental management. Once the SOE data model is extensively implemented, advanced information requirements arisen for new environmental management tasks can be satisfied by systematical integration instead of transforming or reconstructing of databases.

\section{ACKNOWLEDGMENTS}

Authors would like to thank to the National Science Council of the Republic of China, Taiwan for financially supporting this research under the Contract No. NSC 97-2621-M-008-001.

\section{REFERENCES}

Air Pollution Control Act, (2006). ROC (Taiwan) Environmental Law Library. http://law.epa.gov.tw/en/laws/889404502.html Andrew, T.; Richardson, K. A., (2008). Confronting complexity. E:CO, 10 (2), 27-40 (14 pages).

Athanasiadis, I. N.; Mitkas, P. A., (2009). A methodology for developing environmental information systems with software agents, Whitestein Series in Software Agent Technologies and Autonomic Computing: Advanced Agent-Based Environmental Management Systems. Springer-Verlag, 119137.

Brazhnik, O., (2007). Databases and the geometry of knowledge. Data Knowl. Eng., 61 (2), 207-227 (21 pages).

Chen, C. C., (2009). Environmental impact assessment framework by integrating scientific analysis and subjective perception. Int. J. Environ. Sci. Tech., 6 (4), 605-618 (14 pages).

Chen, H. W.; Yu, R. F.; Liaw, S. L.; Huang, W. C., (2010). Information policy and management framework for environmental protection organization with ecosystem conception. Int. J. Environ. Sci. Tech., 7 (2), 313-326 (14 pages).

Chen, Z.; Gangopadhyay, A.; Karabatis, G.; McGuire, M.; Welty, C., (2007). Semantic integration and knowledge discovery for environmental research. J. Database Manage., 18 (1), 4367 (25 pages).

Chu, L. C., (2008). Planning of the baseline information and online reporting integration in the area of air, water, waste and toxic substance. Taiwan Environmental Protection Administration project report No. EPA-96-H102-02-265 (in Chinese).

Connolly, T.; Begg, C., (2004). Database Solutions: A Step by Step Guide to Building Databases, $2^{\text {nd. }}$ Ed. Pearson Addison Wesley, 22-34.

Costanza, R., (1987). Simulation modeling on the Macintosh using STELLA. BioScience, 37 (2), 129-132 (4 pages).

Elmasri, R.; Navathe S. B., (2007). Fundamentals of Database Systems: International Version, $5^{\text {th. }}$ Ed. Pearson Addison Wesley, 29-89 (61 pages).

Hsu, C. W.; Hu, A. H., (2008). Green supply chain management in the electronic industry. Int. J. Environ. Sci. Tech., 5 (2), 205-216 (12 pages).

Huang, B., (2003). An object model with parametric polymorphism for dynamic segmentation. Int. J. Geogr. Inf. Sci., 17 (4), 343-360 (18 pages).

Huang, W. C.; Liaw, S. L., (2004). Development of an objectoriented framework for integrating of environmental data. In the International Conference on Environmental Informatics - ISEIS. Regina, Saskatchewan, Canada. 
Huang, P. S.; Shih, L. H., (2009). Effective environmental management through environmental knowledge management. Int. J. Environ. Sci. Tech., 6 (1), 35-50 (16 pages).

Lee, S.; Wang, T. D.; Hashmi, N.; Cummings, M. P., (2007). Bio-STEER: A semantic web workflow tool for grid computing in the life sciences. Future Gener. Comp. Sys., 23 (3), 497509 (13 pages).

Liaw, S. L.; Huang, W. C.; Wang, L. J., (2006). Development of an event-based system object (EBSO) data model for integration of environmental data. J. Chin. Inst. Environ. Eng., 16 (2), 93-101 (9 pages).

Liaw, S. L.; Kao, J. J.; Tzou, L.; Yu, R. F.; Chang, Y. Y., (2005). The establishment of environmental information standard mechanism, the development of environmental information integration across government departments, planning environmental information application. Taiwan Environmental Protection Administration project report No. EPA-94-L105-02-207 (in Chinese).

Maurer, H.; Halim, Z.; Razak, Z., (2001). From databases to hypermedia. Springer, 12-20.

McLaughlin, C., (2009). Thinking like an ecosystem. Altern. J., 34 (4), 33-36 (4 pages).

Moore, S. B.; Ausley, L. W., (2004). Systems thinking and green chemistry in the textile industry: concepts, technologies and benefits. J. Clean. Prod., 12 (6), 585-601 (17 pages).

Nouri, J.; Karbassi, A. R.; Mirkia, S., (2008). Environmental management of coastal regions in the Caspian Sea. Int. J. Environ. Sci. Tech., 5 (1), 43-52 (10 pages).

Ozel, F.; Kohler, N., (2004). Data modeling issues in simulating the dynamic processes in life cycle analysis of buildings. Automat. Constr., 13 (2), 167-174 (8 pages).

Peckham, J.; Maryanski, F., (1988). Semantic data models. ACM Comput. Surv., 20 (3), 153-189 (37 pages).

Pequet, D. J., (2001). Making space for time: Issues in spacetime data representation. Geoinformatica, 5 (1), 11-32 (22 pages).

Petkov, D.; Petkova, O.; Andrew, T.; Nepal, T., (2008). On the process of combining soft systems methodologies and other approaches in systemic interventions. J. Organisat. Transform. Soc. Chang., 5 (3), 291-303 (13 pages).

Pokorny, J., (2006). Database architectures: Current trends and their relationships to environmental data management.
Environ. Modell. Softw., 21 (11), 1579-1586 (8 pages).

Purvis, M.; Cranefield, S.; Ward, R.; Nowostawski, M.; Carter, D.; Bush, G., (2003). A multi-agent system for the integration of distributed environmental information. Environ. Model. Softw., 18 (6), 565-572 (8 pages).

Rubenstein-Montano, B.; Liebowitza, J.; Buchwaltera, J.; McCawa, D.; Newmanb, B.; Rebeck, K., (2001). A systems thinking framework for knowledge management. Decis. Support. Sys., 31 (1), 5-16 (12 pages).

Seltzer, M. I., (2005). Beyond relational databases. Databases, 3 (3), 50-58 (9 pages).

Shi, W. Z.; Yang, B. S.; Li, Q. Q., (2003). An object-oriented data model for complex objects in three-dimensional geographical information systems. Int. J. Geogr. Inf. Sci., 17 (5), 411-430 (20 pages).

Skyttner, L., (2006). General Systems Theory: Problems, perspectives and practice, $2^{\text {nd. }}$ Ed., World Scientific Publishing Company, 49-105.

Tehrani, S. M.; Karbassi, A. R.; Ghoddosi, J.; Monavvari, S. M.; Mirbagheri, S. A., (2009). Prediction of energy consumption and urban air pollution reduction in e-shopping adoption. J. Food, Agri. Environ., 7 (3 and 4), 898-903 (6 pages).

Toxic Chemical Substances Control Act, (2007). ROC (Taiwan) Environmental Law Library. http://law.epa.gov.tw/en/laws/ 788537580.html

Tuzkaya, G.; Gülsün, B., (2008). Evaluating centralized return centers in a reverse logistics network: An integrated fuzzy multi-criteria decision approach. Int. J. Environ. Sci. Tech., 5 (3), 339-352 (14 pages).

Tzou, L., (2002). Establishing the integrated environmental database. Taiwan Environmental Protection Administration project report No. EPA-91-L105-02-212 (in Chinese).

Tzou, L.; Yu, Y. H.; Liaw, S. L., (2005). The environmental information system data exchange and supply operation project in 2005. Taiwan Environmental Protection Administration project report No. EPA-92-L105-02-210 (in Chinese).

Waste Disposal Act, (2006). ROC (Taiwan) Environmental Law Library. http://law.epa.gov.tw/en/laws/245676169.html

Water Pollution Control Act, (2007). ROC (Taiwan) Environmental Law Library. http://law.epa.gov.tw/en/laws/ 717336547.html

\section{AUTHOR (S) BIOSKETCHES}

Huang, W. C., Ph.D. Candidate, Graduate Institute of Environmental Engineering, National Central University, No.300, Jhongda Rd., Jhongli City, Taoyuan County 320, Taiwan, R.O.C. Email: s9326003@cc.ncu.edu.tw

Liaw, S. L., Ph.D., Full Professor, Graduate Institute of Environmental Engineering, National Central University, No.300, Jhongda Rd., Jhongli City, Taoyuan County 320, Taiwan, R.O.C. Email: slliaw@ncu.edu.tw

Chang, S. Y., Ph.D., Full Professor, Department of Civil and Environmental Engineering, North Carolina A\&T State University, 1601 E. Market St., Greensboro, NC 27411, USA. Email: chang@ncat.edu

Liu, W. L., M.D., Lecturer, Department of Civil and Environmental Engineering, Nanya Institute of Technology, No.414, Sec.3, Jhongshan E. Rd., Jhongli City, Taoyuan County 320, Taiwan, R.O.C. Email: wlliu@nanya.edu.tw

Chen, C. H., Ph.D., Full Professor, Department of Social and Regional Development, National Taipei University of Education, No.134, Sec. 2, Heping E. Rd., Da-an District, Taipei City 106, Taiwan, R.O.C. Email: chchen@tea.ntue.edu.tw

How to cite this article: (Harvard style)

Huang, W. C.; Liaw, S. L.; Chang, S. Y.; Liu, W. L.; Chen, C. H., (2010). Development of the systematic object event data model for integrated point source pollution management. Int. J. Environ. Sci. Tech., 7 (3), 411-426. 